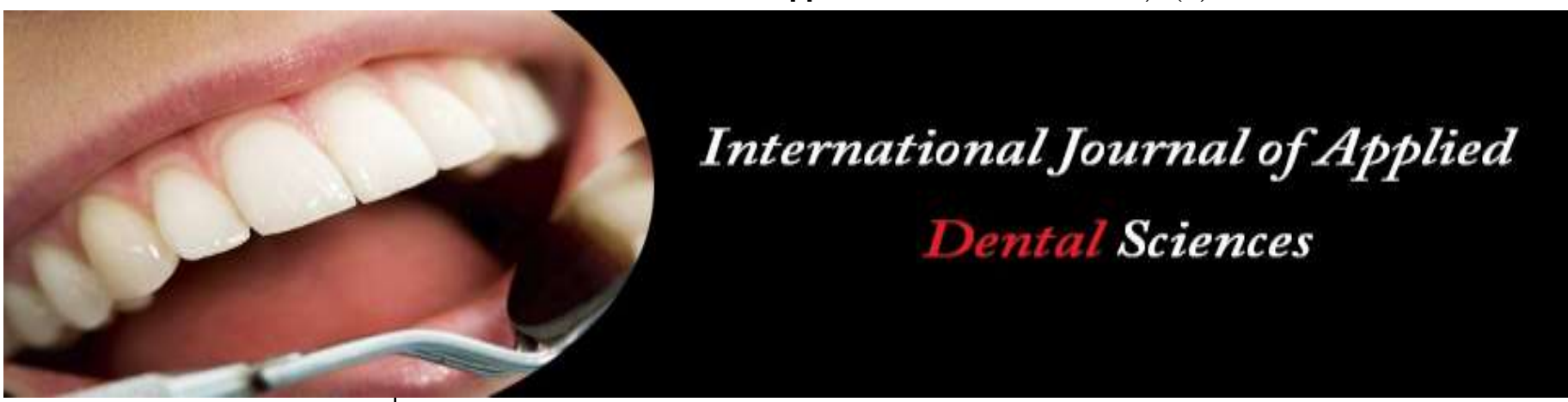

ISSN Print: 2394-7489

ISSN Online: 2394-7497

IJADS 2020; 6(4): 448-451

(C) 2020 IJADS

www.oraljournal.com

Received: 27-08-2020

Accepted: 12-10-2020

Dr. Yoginder Singla

Prof \& HOD, Department of

Prosthodontics, Maharaja Ganga

Singh Dental College Sri

Ganganagar, Rajasthan, India

Dr. Rajni Sharma

MDS STD, Maharaja Ganga

Singh Dental College, Sri

Ganganagar, Rajasthan, India

Corresponding Author:

Dr. Yoginder Singla

Prof \& HOD, Department of

Prosthodontics, Maharaja Ganga

Singh Dental College Sri

Ganganagar, Rajasthan, India

\section{Implant placement in narrow alveolar ridge with ridge split technique: A new approach in implant placement}

\section{Dr. Yoginder Singla and Dr. Rajni Sharma}

DOI: https://doi.org/10.22271/oral.2020.v6.i4g.1100

\section{Abstract}

Dr. Hilt Tatum 1970s introduced a method of ridge splitting or bone spreading, which over a period have been used in implant dentistry for esthetic rehabilitation and implant site preparation in cases of deficient alveolar ridges to satisfy the basic ideal need of hard tissue augmentation for functional and esthetic outcome of implant. In this case report, we describe a case of horizontal ridge augmentation using ridge split and simultaneous implant placement in esthetic maxillary premolar zone.

Keywords: Implant, osteotome, periosteum, ridge expansion/split

\section{Introduction}

A major limitation for successful implant placement remains the problem of inadequate alveolar ridge width. Thus, to satisfy the ideal goals of implant dentistry, the hard and soft tissues need to present in ideal volume and quality ${ }^{[1]}$. In general in the esthetic anterior regions, the labial cortical plates are thinner than the lingual plate and are the first to be removed or resorbed after tooth extraction or trauma. The labial alveolar bone often undergoes rapid reconstruction after natural tooth loss with approximately $25 \%$ decrease in volume during 1 st year, followed by $40-60 \%$ decrease in width in following next 3 years leading to labial cortex of bone more medial than its original position ${ }^{[2]}$. Thus, due to this sequel of resorption after tooth loss jeopardizes the functional and esthetic outcome of treatment. Therefore, augmentation of deficient alveolar ridges is an important aspect of dental implant therapy with the end goal to provide functional restoration that is in harmony with the adjacent natural dentition.

The ridge deficiencies can be horizontal, vertical or combination of both as described by Siberts as classes A, B and C, respectively. Ridge augmentation in deficient alveolar ridge areas are achieved by block graft (autogenous or allograft), guided bone regeneration, distraction osteogenensis and alveolar ridge splitting or expansion with predictable outcomes either alone or in combination ${ }^{[3]}$. The technique of ridge split or ridge expansion was introduced in early 1970s for horizontal ridge augmentation while maintaining the periosteal attachment by carefully expanding the cortical plates. This technique had an added advantage of augmentation and implant placement in a single sitting. Ridge splitting techniques are useful for managing narrow edentulous ridge $(>3.5 \mathrm{~mm})$ for implant placement with predictable outcome in maxilla than in mandible ${ }^{[4]}$. A proper case selection and evaluation is important to achieving a successful surgical and prosthetic outcome. In this case report, we describe a case of horizontal ridge augmentation using ridge split and simultaneous implant placement in esthetic maxillary premolar zone.

\section{Case Report}

A 27-year-old female reported to the outpatient department with the chief complaint of missing upper corner teeth for last 1 year due to renal tubular acidosis leading to tooth evulsion. On intraoral examination, Kennedy's class III edentulous space in 13.14 with class B ridge deficiency was noticed. The patient was moderately built and nourished with no signs of any systemic illness. A complete case history with preoperative procedures consisting of a conventional OPG, cast for ridge mapping, oral prophylaxis and routine blood, and urine investigations were done. 
The patient was interested in pursuing a method that would avoid the use of a secondary donor site for augmentation, a ridge split procedure was planned in order to achieve adequate ridge width to facilitate implant placement. The complete treatment plan was explained to the patient, and duly written consent was obtained.

\section{Surgical Procedure}

The site was anesthetized using $2 \%$ lignocaine with epinephrine. A sharp palatal to midcrestal incision was given followed by raising a full thickness flap so as to expose the ridge crest, which was approximately $4 \mathrm{~mm}$ bucco-palatally [Figure 1]. A 15 no. blade was used for initial mesio-distal incision leaving $1 \mathrm{~mm}$ of colar bone on either side. A disc was used for splitting the buccal and lingual plate and bone spreaders in bone expansion kit (Figure 2) were used for expansion of osteotomy site. The initial length of the bone spreader was prepared approximately $3 \mathrm{~mm}$ deeper than the desired implant length of $11 \mathrm{~mm}$, which was followed by insertion of successive larger diameter bone spreader of 0.5 $\mathrm{mm}$ shorter than the preceding instrument, so as to expand the base of the bone in $\mathrm{V}$ shape [Figure 3]. The visco-elastic nature of the bone was utilized so as to prevent fracture, thus after every sequential osteotome was introduced it was kept in place and removed delicately, maintaining the bone resiliency. Two $3.5 \times 11 \mathrm{~mm}$ implants were placed [Figure 4] and the space between the implants were filled with demineralized freeze-dried bone allograft after placing the cover screw [Figure 5]. Periosteal releasing incision was performed to extend the flap coronally over the implant so as to achieve tension free interrupted sutures for a close approximation. Periodontal pack and postoperative instructions were advised to the patient. Antibiotics and analgesics were prescribed with chlorhexidine mouth wash $0.2 \%$ for 5 days. Pack and sutures were removed after 7 days. Patient was periodically reviewed for 8 months, followed by prosthetic rehabilitation with full ceramic crowns. Figure 8

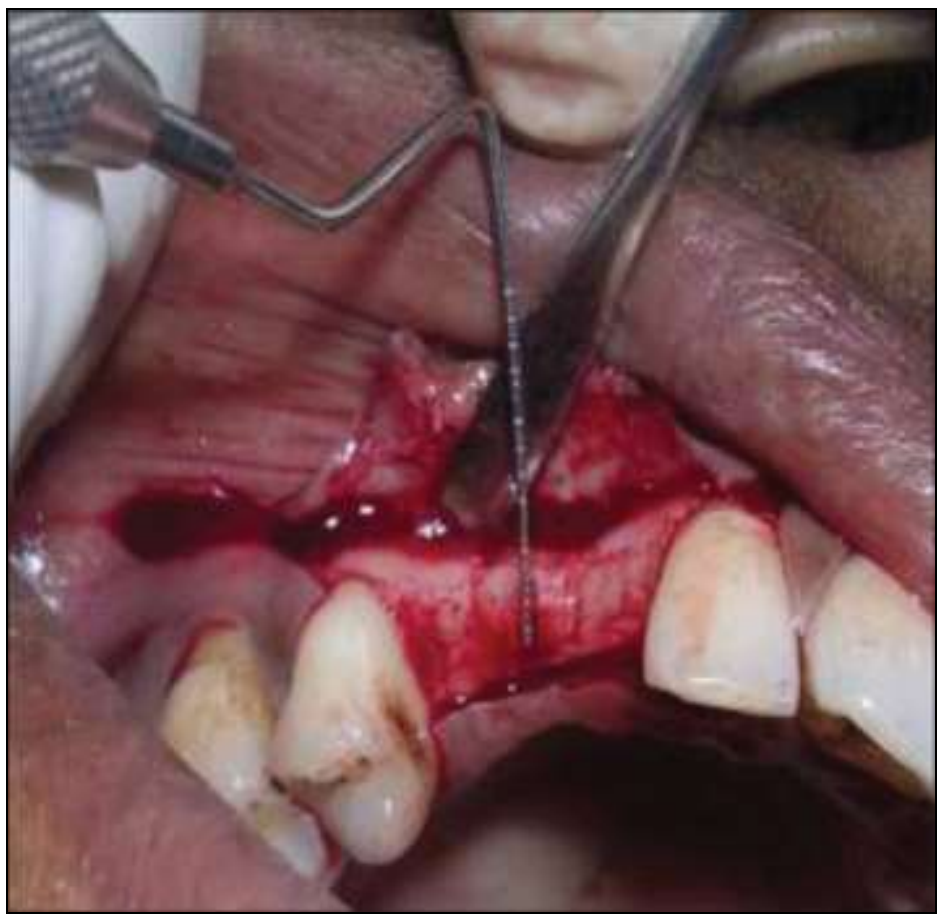

Fig 1: Bucco-lingual deficient alveolar ridge

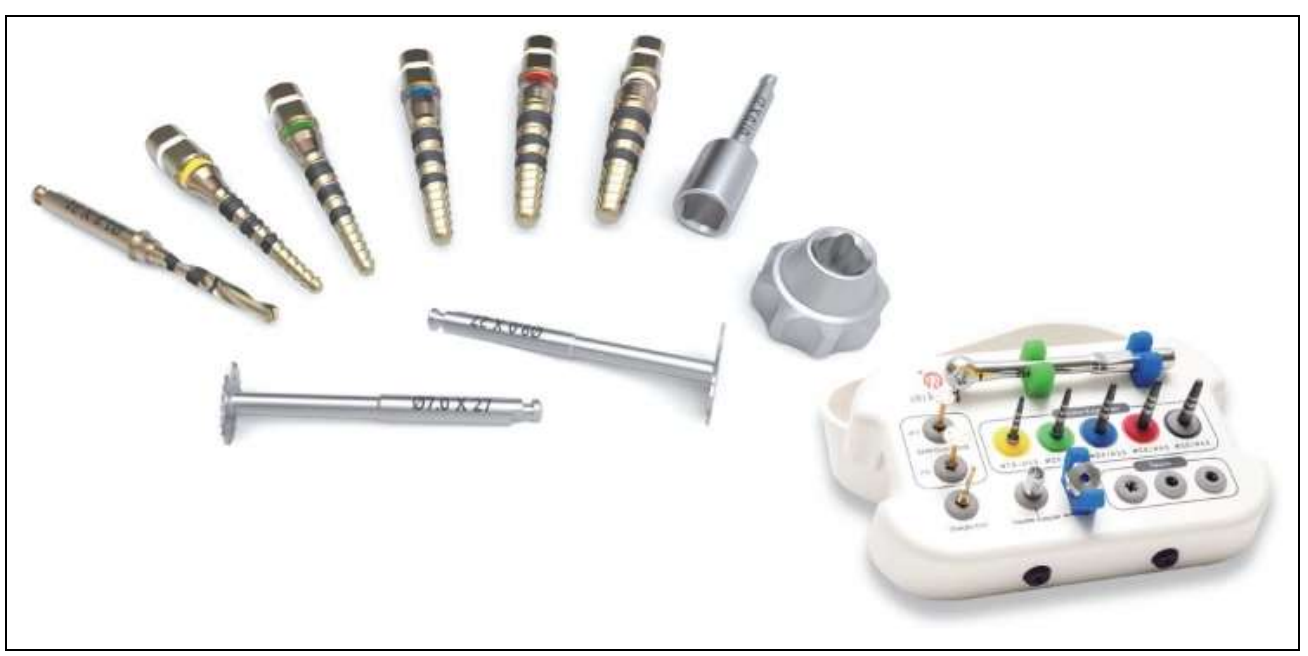

Fig 2: Expansion of osteotomy site 


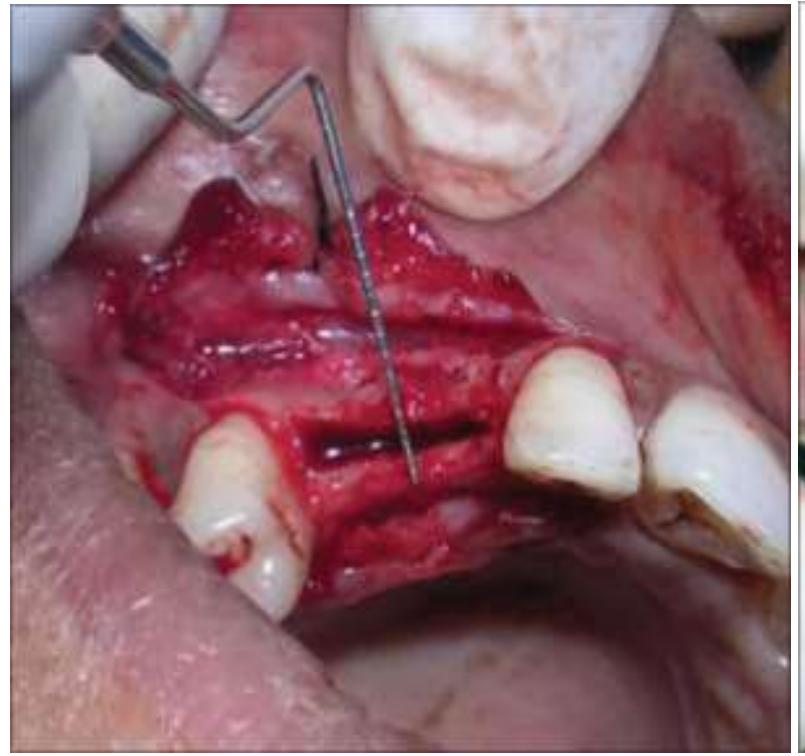

Fig 3: Alveolar ridge after bone spreading with Bone Spreaders

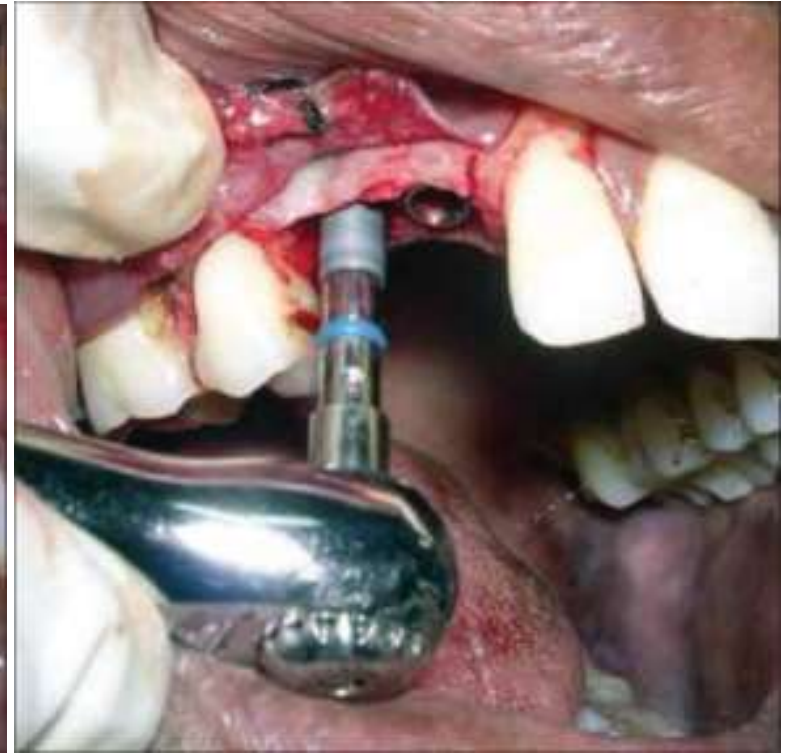

Fig 4: Implant in place

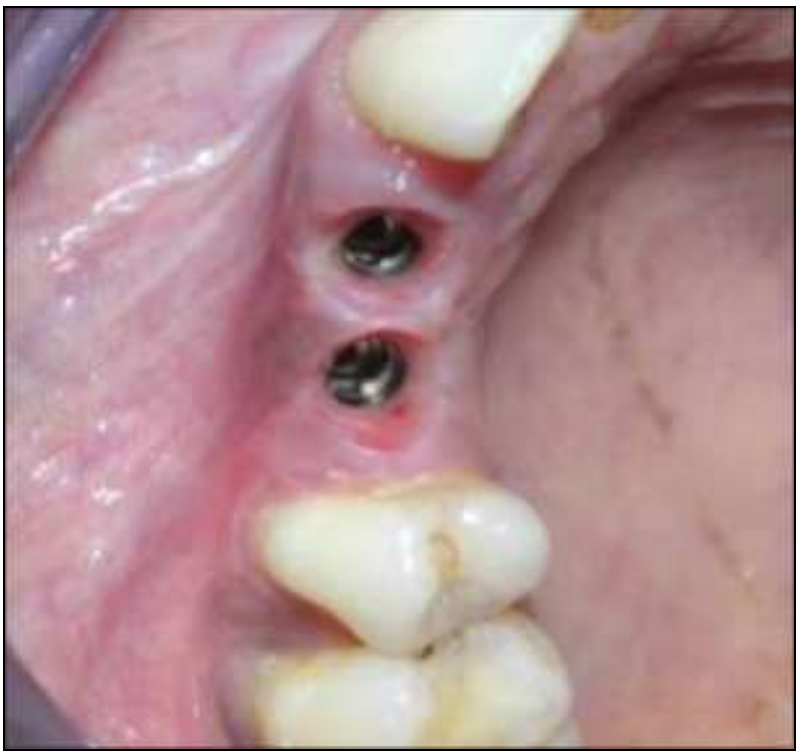

Fig 6: Postoperative 6 months after removal of gingival
Fig 6: Postoperative 6 months after removal of gingival
former
Fig 5: Demineralized freeze-dried bone allograft bone

allograft in space of bone spread

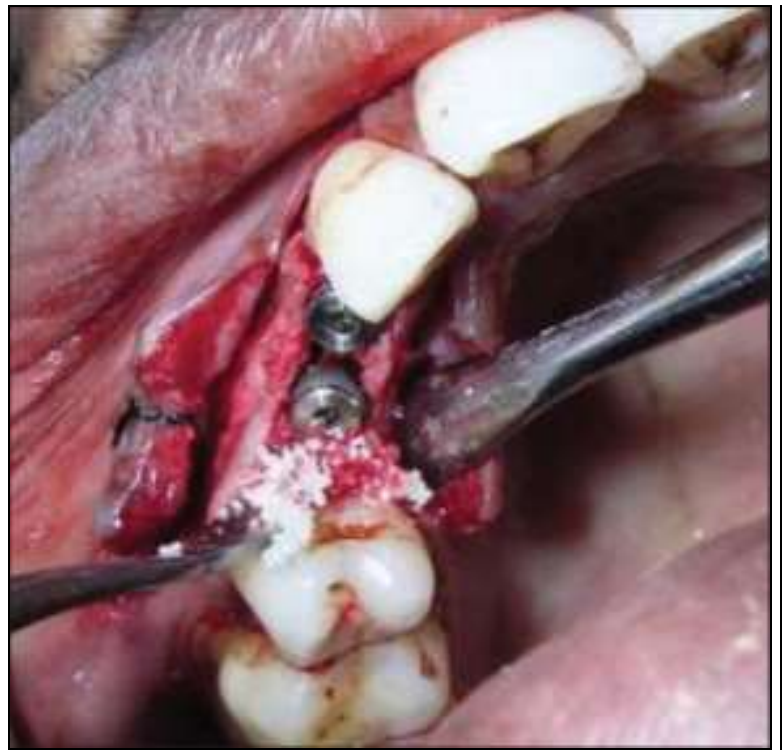

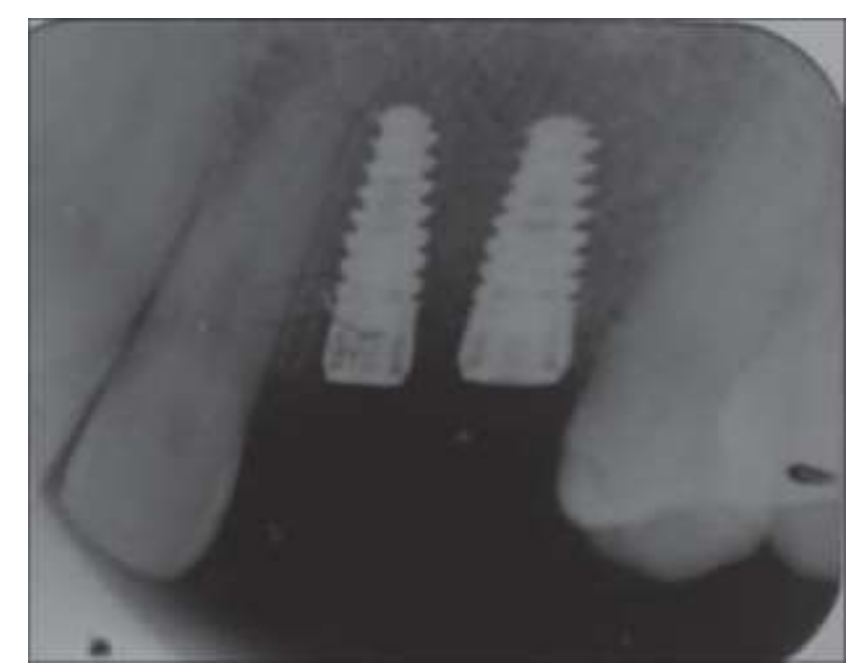

Fig 7: Postoperative 6 months intraoral periapical radiograph

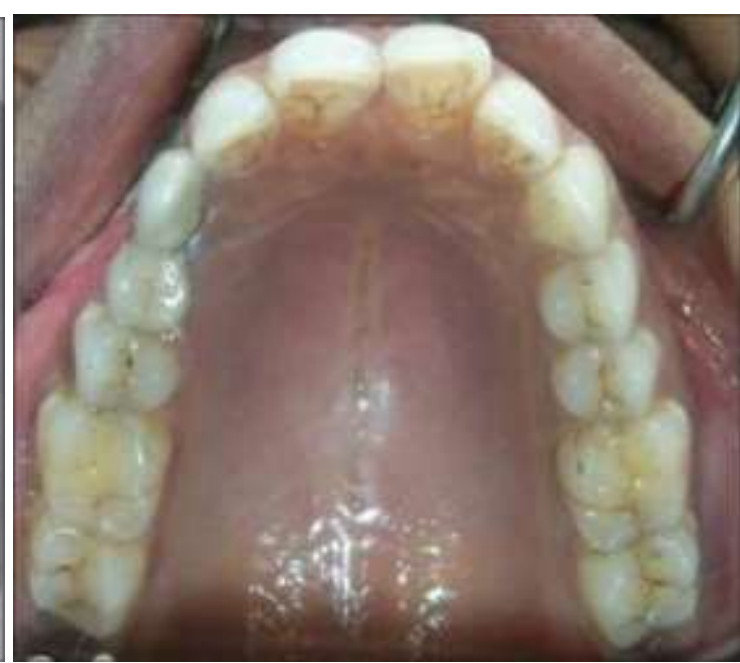

Fig 8: Prosthetic rehabilitation with crown

\section{Discussion}

Augmentation of deficient alveolar ridges is required in implant treatment plan so as to reduce stress at crestal bone region since; faciopalatal bone is often only 4-6 mm wide at the crest with/without an "hourglass" facial deformity ${ }^{[3,5]}$. Therefore, an improved understanding of biomechanical 
requirement for long-term prosthesis survival often requires ridge reconstruction before implant placement. For a favorable outcome, a minimum of $6 \mathrm{~mm}$ ridge width is necessary, thus leading to a minimum of $1-1.5 \mathrm{~mm}$ bone around the implant ${ }^{[6]}$.

Dr. Hilt Tatum 1970s introduced a method of ridge splitting or bone spreading using specific instruments like D-shaped graduated osteotomes/wedges and tapered channel formers. He inserted >5000 maxillary anterior implants using ridge splitting before 1985 wherein, he expanded atrophic ridges $>3$ $\mathrm{mm}$ for simultaneous implant placement and augmentation keeping the periosteum intact ${ }^{[7]}$. Later, Summers and Scipioni et al. in 1994 revived and published articles on edentulous ridge expansion with $98.8 \%$ implant survival rate for over 5 years ${ }^{[7]}$. With the emergence of implant dentistry and introduction of microsaws, piezosaws, and specific ridge split osteotomes this technique has become an integral part of implant dentistry, wherein primarily bone expansion techniques were indicated in regions of division $\mathrm{B}$ bone volume and density of D3 or D4. Bone due to its dynamic viscoelastic nature thinner ridges $(<3.5 \mathrm{~mm})$ can be expanded with better controlled instrumentation with less risk for fracture, trauma and bone perforations. The softer the trabacular bone quality, the lower the elastic modulus and greater the viscoelastic nature of the ridge. Therefore, the less dense the bone, the easier and more predictable the bone expansion ${ }^{[8,9]}$.

Bone expansion provides a more normal facial contour to the region. Bone splitting does not affect the facial and palatal plates equally, the thicker palatal bone is more difficult to manipulate, therefore, the expansion process is primarily in the direction of the thinner facial plate. The bone is prepared 2-4 mm deeper than the final implant length using initial 2 $\mathrm{mm}$ drill later; osteotomes are used to further widen the osteotomy using controlled sequential gentle tapping (about 1 mm for every tap) with a surgical mallet. To remove the bone spreading osteotome it is rotated in the socket and unscrewed with gentle axial tensile force. At $3 \mathrm{~mm}$ diameter of the osteotome and depending on the amount of bone in the facial aspect, the clinical decision is made whether 3.5 or $4 \mathrm{~mm}$ diameter implant to be selected. The initial length of the osteotome, which is $3 \mathrm{~mm}$ deeper than the desired implant length, successive larger osteotome is inserted $0.5 \mathrm{~mm}$ shorter than the preceding instrument; this expands the base of the bone in a $\mathrm{V}$ shape rather than $\mathrm{U}$ shape. This makes it less likely to fracture the labial cortical plate, while placing the implant. The labial tissue should be felt while preparation of the site with osteotome and during implant insertion ${ }^{[7,8]}$. If a perforation occurs, then an autogenous graft and/or barrier membrane is used to augment the site but, the golden rule to follow is when in doubt of perforation, the labial tissue should be reflected, and site should be inspected. The final implant is threaded into position using a slow speed, high torque physiodispenser hand piece. Bone graft can be placed in the space of bone and implant and at the crestal region with membrane to prevent risk of crestal bone loss which also aids in bone remodeling ${ }^{[10]}$.

\section{Conclusion}

There are many methods for augmentation for implant placement in deficient alveolar ridges of which ridge split or spreading are advocated in cases where ridge width is $>3.5$ $\mathrm{mm}$. The most important factor for successful ridge split cases is careful patient selection and bone evaluation. Generally, the site heals similar to fracture repair of bone wherein, the gap is filled by clot that organizes over a period and is replaced with woven bone and later by load bearing lamellar bone at the interphase. Although, this surgical approach may be used in both jaws, it is better suited for the maxilla. Thus, to satisfy the ideal goals of implant dentistry augmentation of deficient alveolar ridges is an important aspect of dental implant therapy with the end goal to provide functional restoration that is in harmony with the adjacent natural dentition as in this case report.

\section{Footnotes}

\section{Source of Support: Nil}

\section{Conflict of Interest: None declared}

\section{References}

1. Sethi A, Kaus T. Maxillary ridge expansion with simultaneous implant placement: 5-year results of an ongoing clinical study. Int J Oral Maxillofac Implants. 2000;15:491-9.

2. Scipioni A, Bruschi GB, Calesini G. The edentulous ridge expansion technique: A five-year study. Int $\mathbf{J}$ Periodontics Restorative Dent. 1994;14:451-9.

3. Lieberman JR, Friedlander GE. 1st ed. Totowa, NJ: (C) Humana Press, Bone Regeneration and Repair, 2005,195$6 \mathrm{p}$.

4. Summers RB. The osteotome technique: Part 4 - Future site development. Compend Contin Educ Dent. 1995;16:1090-1092.

5. Misch CE. Density of bone: Effect on treatment plans, surgical approach, healing, and progressive boen loading. Int J Oral Implantol. 1990;6:23-31.

6. Tatum H. Jr Maxillary and sinus implant reconstructions. Dent Clin North Am. 1986;30:207-29.

7. Scipioni A, Bruschi GB, Giargia M, Berglundh T, Lindhe J. Healing at implants with and without primary bone contact. An experimental study in dogs. Clin Oral Implants Res. 1997;8:39-47.

8. Summers RB. A new concept in maxillary implant surgery: The osteotome technique. Compend Contin Educ Dent. 1994;15:152-60.

9. Misch CE. 2nd ed. St. Louis: The CV Mosby Company, Contemporary Implant Dentistry, 1999, 3-11p.

10. Belser UC, Buser D, Hess D, Schmid B, Bernard JP, Lang NP. Aesthetic implant restorations in partially edentulous patients: A critical appraisal. Periodontol 2000. 1998;17:132-50. 